\title{
A 3-Year Evaluation of Taste Aversion Coyote Control in Saskatchewan
}

\author{
CARL R. GUSTAVSON, JAMES R. JOWSEY, AND DONALD N. MILLIGAN
}

\section{Abstract}

Taste aversion programs using lithium chloride $(\mathrm{LiCl})$ in sheep baits and carcasses have been applied in Washington to one sheep herd for 2 years; applications have been made in California and in Saskatchewan on 46 herds over 3 years. Ten of these 46 herds were a vailable for statistical analysis, indicating a significant reduction in the percent of sheep lost to coyotes. All applications have suggested reduced sheep losses to coyotes (Canis latrans). This method of predation control may cost less than traditional techniques, save sheep, and should allow coyotes to carry out positive functions in the ecosystem.

Our purpose has been to alter the predatory behavior of coyotes (Canis latrans) in "natural" settings to reduce sheep losses. Our working model (Gustavson et. 1979) was based on experimental evidence from rats in the laboratory. Data from most field settings remain indicative, and subjective, even when precautions are taken. Laboratory findings involve objectively measured, discrete responses in controlled settings. Laboratory studies have a high degree of control resulting in internal validity but may lack the external validity needed for generalization to the field. We conducted laboratory studies (Gustavson et al. 1974; Gustavson et al. 1976) under varied conditions to improve external validity while maintaining confidence in our conclusions. Several field investigations have been conducted with primary applications being made by researchers, (Gustavson, et al. 1976; Ellins et al. 1977; Stream 1976).

The first application (Gustavson et al. 1976) was conducted in southeastern Washington. A $12.15-\mathrm{km}^{2}$ ranch was baited at approximately 1 bait $/ 0.04 \mathrm{~km}^{2}$. Some difficulty was experienced in evaluating sheep losses to coyotes. There was no less than a $40 \%$ decrease, and as much as a $62 \%$ decrease in sheep lost to coyotes. A second researcher-oriented study (Ellins et al. 1977) was conducted in Antelope Valley, California. This study used ten bait stations for the entire valley and reduction in expected losses was demonstrated, even on nearby herds that had not been treated.

Following our application in Washington (Gustavson et al. 1976), the Washington Game Department replicated our study on the same ranch (Stream 1976). The ranch was baited at a level of one bait $/ 0.345 \mathrm{~km}^{2}$ and the baits were consumed. The game agent experienced difficulties in evaluating losses to coyotes, and in order to avoid conflict with the rancher, the data were reported in a format different from Gustavson et al. (1976) above. When these data are recalculated as reported above (Gustavson et al. 1976), a

Authors are affiliated with the Department of Psychology, North Dakota State University, Fargo, North Dakota 58105; the Animal Industry Branch, Saskatchewan Department of Agriculture, Regina, Saskatchewan.
40-60\% reduction was again demonstrated.

These three studies represented a standardized procedure. The experimenter (scientist or game agent) baited the range, recorded consumption of sheep baits, and consulted with the ranchers to evaluate losses. This evaluative procedure has two problems which make interpretation of the results difficult: (1) The single flock - pre treatment - post treatment design makes statistical evaluation of the significance of reductions impossible, (2) The measurement of sheep losses is particularly susceptible to observation biases. These difficulties could be rectified with an appropriate experimental design. Ideally, applications should be made on at least 20 geographically separate herds found to be equivalent across many parameters such as geography, climate, size of flock, coyote density, and management practice. These flocks would be randomly assigned to one of five groups for a 3-year treatment program. One set of four flocks would be treated with $\mathrm{LiCl} /$ sheep baits and carcasses. A second set of 4 flocks would receive $\mathrm{LiCl} /$ horse baits, a third set would receive sheep baits without chemicals, the fourth set would receive $\mathrm{NaCl}$ /sheep baits and carcasses, and finally no baiting. All areas would be treated with equivalent numbers of baits. All sheep and coyotes would be equipped with radio telemetry devices for identification and location. Treatments would be conducted in a double blind design to reduce the influence of experimenter bias on the part of trained evaluators in the field. Daily counts of losses and baits consumed would be recorded. Results from this type of study could be expected to produce somewhat unequivocal results on yearly losses and indicate which component of the treatment program was responsible for reductions if they occurred.

Two major practical problems make the implementation of this design in the field unlikely if not impossible. Both problems are financial. A minimum of 35 full-time researchers would be required to conduct this study, 32 field workers, one person to make baits and prepare solutions for carcass lacing, one person to control the double-blind procedures, and an overall coordinator. Personnel costs for this project would be very high. The second problem requires a financial solution to an ethical problem. In order to conduct this study, all other forms of predator control must be suspended. If privately owned flocks were to be used, prudence would dictate that all losses be financially reimbursed. Another solution to this problem would be to have project-owned flocks on rented land. Both solutions would be expensive indeed.

Until large sums of money become available for this research or serendipitous arrangements occur which would provide the number of fulltime volunteers, land, and sheep required for the study, it would seem sage to continue evaluation programs under less than optimal conditions. Several possible research plans are 
Table 1. Location, land area, flock size, and reported percent of fock lost to coyotes for 10 ranches treated with LiCl in Saskatchewan.

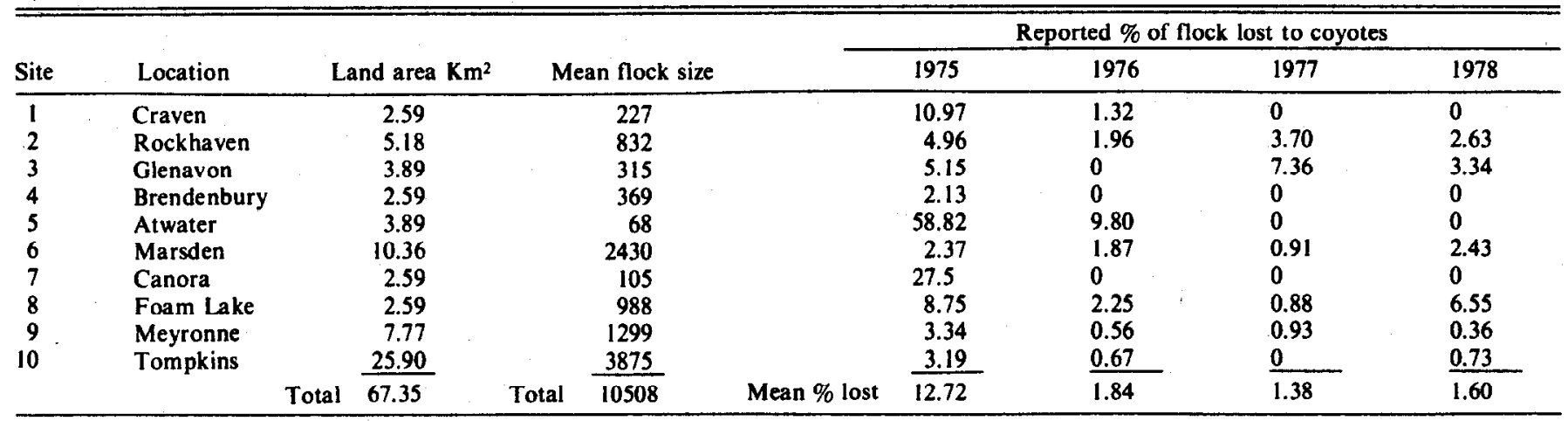

available which restrict the interpretation of information but do not negate all utility of the studies. Rather than attempting to control for the effect of certain variables, it is often possible to attempt to correct for them. The evaluation represented in this paper is restricted in interpretation, but valuable. Discussion of these restrictions and the utility of the data will be postponed to the conclusion of the paper.

\section{Method}

During the winters of 1976,1977 , and 1978, quantities of baits composed of approximately $100 \mathrm{~g}$ ground sheep meat containing $6 \mathrm{~g}$ of $\mathrm{LiCl}(1976)$ and $4 \mathrm{~g}$ of $\mathrm{LiCl}$ (1977 and 1978) wrapped and tied in sheep hide were made and frozen for preservation. Beginning in April of each year the baits were distributed to wool growers that had contacted the Animal Industry Branch of Saskatchewan Agriculture Department. Each manager was assisted in bait distribution. Demonstrations of carcass injection were provided. A supply of $\mathrm{LiCl}$ for the injection of more carcasses was left with each manager. Weather conditions necessitated that some pastures in the northern portion of the province be baited by airplane. Pastures in the southern portions of the province were baited by horseback, or irom a pickup truck. When possible, baits were placed at coyote "digs" under fences. Managers were instructed to inject dead sheep and lambs with $\mathrm{LiCl}$ or to dispose of them.

Pastures were targeted to be baited at 1 bait $/ 0.162 \mathrm{~km}^{2}$. Baiting was restricted to the pastures, except at site 11 where permission to bait a surrounding cattle area was granted. This "buffer" area of baiting may be useful when possible. Cooperation from the managers was good, even though many were somewhat skeptical of the proposed technique.

Many of the pastures were subjected to a detailed examination in June 1976 and many of the original baits had been removed. Many sites were discovered in which wool remains were similar to those found in our previous field studies, and indicated coyote bait consumption.

\section{Results}

During the 3-year program a total of 46 herds have been treated with $\mathrm{LiCl} /$ baits and $\mathrm{LiCl} /$ laced carcasses. Twenty-four of these herds were treated in 1977 and/or 1978 only. Twenty-two herds began partcipation in 1976. Of these 22 herds, three did not finish the study that year, three herds did not have 1975 coyote loss records, three herds did not remain with the project through 1978 , baits were distributed at extremely low densities for one herd, one herd suffered very high identified domestic dog losses during 1978 before alternative elimination could be initiated, and finally, this manager and one other refused to maintain continued baiting or carcass lacing through each season, even though baits were placed yearly.

Ten herds have completed the 3-year program and fulfilled the necessary requirements for statistical analysis. Table 1 shows the general geographical location, the mean number of sheep, the land area baited, and the percent of the flock reported lost to coyotes in
1975, 1976, 1977, and 1978, for each of these 10 herds. A one-way analysis of variance for ranked data (Winer 1962) indicated that the decrease in sheep lost to coyotes across years was significant, $X^{2}$ (3) $=17.73, p<.005$.

An economic estimate can be made for the results of this program on these 10 herds. Provincial standards suggest the value of sheep at $\$ 40 /$ head. At this rate, $\$ 53,465$ worth of sheep were lost in 1975 compared to a mean of $\$ 6,760$ / per year in the same herds in 1976,1977 , and 1978. This represents a decrease of $\$ 46,705 /$ year. In previous years, the province estimated the cost of the 1080 poisoning program at $\$ 250$ per herd. The province estimated the cost of the taste aversion program at $\$ 25-35 /$ herd/year. The overall reduction in cost of predator control would be $86 \%$ to $90 \% /$ year.

\section{Discussion}

The preliminary reports of this study and other field investigation of taste aversion coyote control have been criticized on the basis of a lack of experimental control groups for comparison, as though this were a decisive condemnation (Griffiths, et al. 1978).

While "sham" controls have not been used, other control procedures have been used for comparison (see Ellins et al. 1978). A simple one-group placebo procedure is an inadequate control, but the lack of any control procedure is not the important issue that must be considered before a discussion of the results of this study. Important and meaningful scientific research can be conducted without the use of experimental techniques. McK. Agnew and Pyke (1969) very clearly described the value of, and occasion for, the use of observational techniques:

It should not be surmised that because naturalistic observation is employed to study somewhat gross behavior units, and requires little in the way of elaborate equipment, it is no longer in vogue or has outlived its usefulness, or it is a simple method and needs little training. All of these inferences are erroneous. There are many areas of study in which it is impossible, for ethical, moral, political, or practical reasons, for the researcher to manipulate events or to experiment. In addition, certain types of information can only be obtained in field or naturalistic studies. For example, if we want to investigate the phenomenon of hibernation, or famine, or juvenile gangs, we must use naturalistic observation for at least some portion of our study. . . Although at times this method is comparable to a crude sieve, it is still a valuable source of important and durable data in the hands of a skilled researcher.

One obvious advantage of this method is its superiority to casual observation and hit-and-miss recording or tabulating of events. A second advantage is that it does not require that events necessarily be manipulated or controlled; therefore, all sorts of subject matters, normally taboo to experimental science, become open to this form of study. Another advantage of a thorough understanding of this method is in terms of the relationship of this approach to other methods. The four principles of naturalistic observation (detailed observation, accurate recording, non-participant observation, and grouping or classification) have application to all the other sieves of science in greater or lesser degrees. Often the data gathered by the method of naturalistic observation provides guidelines for later inquiry with more sophisticated sieves. . . Finally, this method can 
be practiced by the. . . scientist who has limited resources. In attempting to be analytical, passive, and accurate, it is often amazing what fascinating chunks of information we can produce.

In the most conservative terms, the results of this evaluation indicate that $\mathrm{LiCl} /$ baits and $\mathrm{LiCl}$ sheep carcasses placed in sheep flock areas, along with coyote trapping and shooting techniques used as in the past, reliabily reduced reported losses to coyotes compared to reported losses when these flock areas are treated with 1080 poison baits along with trapping and hunting techniques. The design of this evaluation does not allow for the specification of the program variables which are responsible for the loss reduction. Observer biases and reliability may have affected the reporting of sheep lost to coyotes in this study. These observers were sheep managers that had approached the Animal Industry Branch for permission to use poison 1080 on their range. They were openly skeptical about the $\mathrm{LiCl}$ alternative offered them. Under these circumstances observer biases might be expected to be in the direction opposite the effect reported here. No obvious changes in the trapping or hunting successes could be ascertained from the very general information available to the project. Some increases in the number of coyotes killed/year in the province could be speculated because of increasing prices for coyote pelts. However the 1080 program was reduced in the research areas, thus eliminating one effective mortality factor. This evaluative design does not allow specification of the effect changes in activity on the ranch may produce due to the different baiting systems involved in 1080 and $\mathrm{LiCl}$ use. Both baiting programs employ similar if not identical procedures. We cannot demonstrate that taste aversion conditioning was responsible for changes in reported losses, as opposed to repellent or other possible processes involved in $\mathrm{LiCl}$ placement. However, if parsimony is to valued in scientific activities, the experimental results obtained in laboratory studies with coyotes, wolves, ferrets, red-tailed hawks, and albino rats must also be considered in the interpretation of our field observation. The weight of this evidence makes an aversion explanation more plausible than other alternatives.

Whatever the mechanism involved, the information collected in Saskatchewan suggests that a successful coyote $\mathrm{LiCl}$ control program can be established which is economically superior to other ongoing programs. It should consist of a baiting program prior to the introduction of sheep on the range. Baits should have at least
$100 \mathrm{~g}$ ground sheep, $4 \mathrm{~g}$ lf $\mathrm{LiCl}$, wrapped and tied in an untreated piece of sheep hide. These baits should be distributed at about 1 bait $/ 0.162 \mathrm{~km}^{2}$ along fence lines, coyote digs in fence lines, gates and coyote run areas. Baits should be replaced when removed by coyotes. Sheep killed by coyotes should be immediately "laced" with $\mathrm{LiCl}$ as should stillborn lambs or other sheep losses. If carcasses are not "laced", they should be disposed of to prevent scavenging.

Future research in the laboratory using procedures prescribed by previous research on many species should be used to develop new techniques for application in wild canids and other animals. In the field, careful recording of the circumstances and events which occur during applied projects should provide a data base that will allow the classification of circumstances and techniques which are likely to produce positive outcomes and specify the important variables that should be controlled if the opportunity should arise to conduct an adequate field experiment.

\section{References}

Ellins, S.R., S.M. Catalano, and S.A.Schechinger. 1977. Conditioned taste aversion: a field application to coyote predation on sheep. Behav. Biol. 20:91-95

Ellins, S.R., C.R. Gustarson, and J. Garcia. 1978. Conditioned taste aversion in predators: response to Sterner and Shumake. Behav. Biol. 24:554-556.

Griffiths, R.E., Jr., G.E. Connolly, R.J. Burns, and R.T. Sterner. 1978. Coyotes, sheep and lithium chloride. Proceedings of the Vertebrate Pest Conference 8:190-196.

Gustavson, G.R., J. Garcia, W.W. Hankins, and K.W. Rusiniak. (1974). Coyote predation control by aversive conditioning. Science 184:581-583.

Gustavson, C.R. D.J. Kelly, M.Sweeney, and J. Garcia. 1976. Prey lithium aversion I: Coyotes and wolves, Behav. Biol. 17:61-72.

Gustavson, C.R., L.R. Brett, and D.J. Kelly, 1979. A working model and experimental solutions to the control of predatory behavior. In: $\mathrm{H}$. Markowitz and V. Stevens (Eds.) Studies of Captive Wild Animals, Chicago: Nelson Hall.

McK. Agnew, N. and Pyke S. 1969. The Science Game. New Jersey: Prentice-Hall Inc., p. 63.

Stream, L. 1976. 1976 Lithium chloride coyote taste aversion experiment in Whitman County Washington: Final Rep. to the Washington Dep. of Game.

Winer, B.J. 1962. Statistical Principles in Experimental Design. New York: McGraw Hill Book Co., p. 136-137. 